\title{
Diseño y monitoreo en tiempo real de un biodigestor, aplicado a las condiciones ambientales de Hermosillo
}

\section{Design and monitoring in real time of a biodigester, applied to the environmental conditions of Hermosillo}

\author{
MONTIJO-VALENZUELA, Eliel Eduardo $\dagger^{*}$, RAMÍREZ-TORRES, Flor, RIVERA-LANDAVERDE, \\ Rodolfo Ulises y RAMÍREZ-CORONEL, Fernando Joaquín
}

Instituto Tecnológico de Hermosillo / Tecnológico Nacional de México, Departamento de Metal Mecánica

ID $1^{\text {er }}$ Autor: Eliel Eduardo, Montijo-Valenzuela/ ORC ID: 0000-0001-8538-0767, CVU CONACYT ID: 803185

ID $1^{\text {er }}$ Coautor: Flor, Ramírez Torres/ ORC ID: 0000-0003-0391-9357

ID $2^{\text {do }}$ Coautor: Rodolfo Ulises, Rivera-Landaverde / ORC ID: 0000-0001-9230-2441, CVU CONACYT ID: 634328

ID $3^{\text {er }}$ Coautor: Fernando Joaquín, Ramírez-Coronel / ORC ID: 0000-0003-0535-0504, CVU CONACYT ID: 709298

DOI: $10.35429 /$ JOIE.2019.9.3.19.33

Recibido 13 de Febrero, 2019; Aceptado 31 de Marzo, 2019

\begin{abstract}
Resumen
El objetivo general de esta investigación es sensar y monitorear las variables principales que afectan los procesos de biodigestión; temperatura $(\mathrm{T})$, potencial de hidrogeno $(\mathrm{pH})$, humedad, volumen y presión dentro del bioreactor, y correlacionarlas con la producción de biogás, mediante un sistema de monitoreo en tiempo real. Para el desarrollo del diseño del sistema se recopiló información de las variables y factores que afectan el proceso de biodigestión. Posteriormente se seleccionaron los instrumentos y elementos integrales del sistema de monitoreo y sensado, que incluyen un sensor LM35 para medición de temperatura, un electrodo de medición de tipo analógico industrial para medición de $\mathrm{pH}$, un FC-28 para la medición de la humedad, un sensor electroquímico MQ2 para medición de producción de metano, un sensor ultrasónico HC-SR04 para medición de nivel (relacionado al volumen del biodigestor) y un sensor piezoeléctrico MPX2202DP case 344C-01 para medición de presión. Los valores captados por los sensores, serán visualizados en tiempo real en una aplicación de Visual Studio y guardados automáticamente en una base de datos. La integración del sistema fue probada experimentalmente en un lapso de 12 días en la ciudad de Hermosillo, Sonora, México, en donde se obtuvieron mediciones para comparación con otros autores.
\end{abstract}

Monitoreo de variables en tiempo real, Biodigestor, Condiciones ambientales de Hermosillo

\begin{abstract}
The general objective of this research is to sense and monitor the main variables that affect biodigestion processes; temperature, hydrogen potential $(\mathrm{pH})$, humidity, volume and pressure within the bioreactor, and correlate them with the production of biogas, through a real-time monitoring system. For the development of the system design, information was collected on the variables and factors that affect the biodigestion process. Subsequently, the instruments and integral elements of the monitoring and sensing system were selected, all these electronic devices for commercial use and mentioned below. An LM35 sensor for temperature measurement, an industrial analog type measuring electrode for $\mathrm{pH}$ measurement, an $\mathrm{FC}-28$ for moisture measurement, an MQ2 electrochemical sensor for measurement of methane production, an HC-SR04 ultrasonic sensor for level measurement (related to the volume of the biodigester) and a piezoelectric sensor MPX2202DP case 344C-01 for pressure measurement. The values captured by the sensors will be displayed in real time in a Visual Studio application, and will be automatically saved in a database. The integration of the system was experimentally tested in a span of 12 days in the city of Hermosillo, Sonora, Mexico, where measurements were obtained for comparison with other authors.
\end{abstract}

Monitoring of variables in real time, Biodigester, Environmental conditions of Hermosillo

Citación: MONTIJO-VALENZUELA, Eliel Eduardo, RAMÍREZ-TORRES, Flor, RIVERA-LANDAVERDE, Rodolfo Ulises y RAMÍREZ-CORONEL, Fernando Joaquín. Diseño y monitoreo en tiempo real de un biodigestor, aplicado a las condiciones ambientales de Hermosillo. Revista de Ingeniería Innovativa. 2019. 3-9:19-33

\footnotetext{
*Correspondencia al Autor (Correo electrónico: elielmontijo@gmail.com)

$\dagger$ Investigador contribuyendo como primer Autor.
} 


\section{Introducción}

Actualmente los hidrocarburos son la principal base energética de la sociedad, con ellos se mueven desde pequeños automóviles hasta las grandes industrias, sin embargo, no son energías renovables, ya que una vez agotados, no se pueden recuperar. Ante esta problemática, muchos científicos a nivel mundial están estudiando otro tipo de energías para poder seguir "moviendo al mundo", entre ellas destaca la energía nuclear, pero hay otro tipo de energías conocidas como "inagotables", ya que estarán disponibles mientras el planeta Tierra exista con las características actuales, algunas de ellas son la energía proveniente del Sol, la energía geotérmica, la energía eólica y la energía oceánica, y en formas más recientes, la utilización de material orgánico para la producción de biogás a través de un proceso bioquímico de fermentación dentro de depósitos cerrados carentes de oxígeno, llamados biodigestores.

Este tipo de energía con ayuda de la tecnología necesaria puede convertirse en calor, electricidad o energía mecánica. Con sistemas de generación de biogás, se aprovechan fuentes de energía existentes, como los desechos de las granjas piscícolas, bovinas o avícolas, valorizando sus potencialidades desde un punto de vista económico, social y ambiental.

El estado de Sonora se caracteriza por ser una zona con productividad agrícola y ganadera, para 2014, las actividades primarias (agricultura, cría y explotación de animales, aprovechamiento forestal, pesca y caza), representaron un $7.3 \%$ del Producto Interno Bruto (PIB) total del estado (Instituto Nacional de Estadística y Geografía, 2018), lo que lo hace una entidad potencial en el aprovechamiento de la energía de la biomasa, obtenida de productos y residuos animales y vegetales; como la energía contenida en los cultivos, residuos agrícolas y estiércoles.

En (López Gálvez, 2015), se establece que dentro del inventario de residuos producidos en Sonora, susceptibles de generar biogás como fuente energética, son producidas 883,714.97 toneladas equivalentes de petróleo (TEP) anuales.
Sin embargo, señala que aunque está disponible, no toda la materia esta alcance para el uso deseado, siendo un total de 738,371.71 TEP las que pueden ser aprovechadas, principalmente en las zonas centro y sur del estado, comprendidos los municipios de Cajeme, Hermosillo, Etchojoa, Benito Juárez, Bácum, Huatabampo y Guaymas, comprendiendo el 93\% del potencial energético accesible al año, equivalente a 8,221,291.93 MWh/año, cifra que podría representar hasta el $74 \%$ del total de las ventas en Sonora en un año.

Sujeto a esta justificación, la biomasa generada en el estado puede ser aprovechada en forma de biogás; "una mezcla conformada principalmente por $\mathrm{CH}_{4}(50 \%-70 \%)$ y $\mathrm{CO}_{2}$ (25\%-40\%), que se genera por el proceso biológico de biodigestión anaerobia, que consta de una serie de reacciones bioquímicas en la que residuos orgánicos son degradados o consumidos por un conjunto de microorganismos" (Red Mexicana de Bioenergía, 2016), mediante tecnologías de biodigestión, principal motivación para desarrollar este tema de investigación, ya que se cuenta con materia prima generada por las actividades primarias en el estado, susceptible de producción de biogás, que actualmente no está siendo aprovechada, por lo que se podrían fabricar granjas autosustentables, sobre todo, aquellas que se encuentran en zonas en donde la electricidad es difícil de trasladar. Otro tema de importancia es la gestión de los residuos, ya que, al no ser aprovechados, la gestión que se les da es poco eficiente, incluso son almacenados al aire libre en fosas.

Como resultado de esta investigación se pretende obtener un diseño de un biodigestor automatizado que sense y cree un historial del proceso de biodigestión, todo esto de forma remota, en cuyo caso, puede estar siendo analizado y/u operado desde un centro de mandos. El diseño del sistema de biodigestión se realizará en la ciudad de Hermosillo Sonora, con coordenadas $29^{\circ} 5^{\prime} 44^{\prime \prime} \mathrm{N}, 110^{\circ} 57^{\prime} 3^{\prime \prime} \mathrm{W}$. El principal aporte de esta investigación es el monitoreo en tiempo real de las variables del proceso de biodigestión, mediante la automatización del proceso, implementando sensores y actuadores de bajo costo, y los principales beneficiados son los agricultores y ganaderos de la región del Estado de Sonora. 
Para el cálculo de volumen total del biodigestor, se tomó como referencia a (Campos, 2011). Para efectos experimentales, se especifica que el total de materia orgánica es de 10 litros, la cantidad de agua es de 1 litro y la retención para el experimento es de 12 días, dando como resultado un reactor con un volumen de 20 litros, utilizando material plástico para las paredes. Contará con un agitador en forma de hélice, que tendrá la función de revolver la biomasa introducida al reactor para que se homogenice la mezcla, este será accionado por un motor.

En la parte superior tendrá conectado un tubo con un medidor mecánico (analógico) de flujo de gas, el cual contabilizará el biogás producido durante el proceso, además, dentro del tubo se colocará el sensor MQ2, el cual detectará el porcentaje de metano producido en ppm (partes por millón) y un sensor MPX2202DP case 344C-01 para medir la presión.

Se colocará un sensor en la parte interna del recipiente, que nos indicará el nivel al que se encuentra el reactor. Internamente y de forma directa con la biomasa, se colocarán un sensor de temperatura LM35, un sensor de humedad FC$28 \mathrm{y}$ un sensor de $\mathrm{pH}$.

Todo el proceso será monitoreado en tiempo real, en donde se mostrarán las variables de $\mathrm{pH}$, temperatura, nivel, total de gas producido, humedad y presión. Todos los sensores estarán conectados a la placa de Arduino®. Los valores que se detecten en los sensores, además de poder ser visualizados en tiempo real, se guardarán de forma automática en una base de datos, para llevar un registro histórico de las variables mencionadas.

\section{Desarrollo metodológico}

\section{Clasificación y selección de vaiables y factores para el diseño del biodigestor}

Los procesos de biodigestión anaeróbica, dependen de las condiciones y variables del medio donde se reproducen las bacterias metanogénicas. Según (Rivas Solano, Faith Vargas \& Guillén Watson, 2010), (Varnero Moreno, 2011) y (Gutiérrez García et al., 2012).
Los principales factores que afectan la producción de biogás son el tipo de sustrato (materia prima), temperatura de operación del sustrato, el tiempo de retención, los niveles de acidez y alcalinidad $(\mathrm{pH})$, la relación carbononitrógeno del sustrato, el agregado de inoculantes, el grado de mezclado, el contenido de solidos totales y la presencia de inhibidores. Para este diseño se considerarán las variables de temperatura, $\mathrm{pH}$, nivel de biomasa y la humedad del proceso, y como factores se determinarán el tipo de sustrato empleado para el diseño del biodigestor, el tiempo de retención, la relación de carbono nitrógeno del sustrato y el grado de mezclado.

\section{Temperatura de operación del biodigestor}

El $48 \%$ del estado de Sonora, presenta clima seco y semiseco localizado en la Sierra Madre Occidental, el $46.5 \%$ presenta clima muy seco, localizado en las Llanuras Costera del Golfo y Sonorense, $4 \%$ es templado subhúmedo se encuentra hacia el este del estado y el restante $1.5 \%$ presenta clima cálido subhúmedo localizado hacia el sureste (INEGI, 2017). Bajo la clasificación climática de Köppen, Hermosillo presenta un clima desértico caliente (BWh), según el Servicio Meteorológico Nacional, (2017). Las temperaturas de Hermosillo son extremosas, se alcanzan temperaturas que pueden ser inferiores a los $5^{\circ} \mathrm{C}$ en invierno y superiores a los $38^{\circ} \mathrm{C}$ en verano (ver tabla 1 ).

\begin{tabular}{|c|c|c|c|c|c|c|}
\hline & Ene & Feb & Mar & Abr & May & Jun \\
\hline $\mathrm{T}_{\text {mínima }}$ & 4.8 & 8.4 & 9.4 & 11.5 & 14.2 & 21.4 \\
\hline $\mathrm{T}_{\text {máxima }}$ & 22.9 & 29.7 & 29.9 & 31.3 & 33.9 & 38.9 \\
\hline $\mathrm{T}_{\text {media }}$ & 13.9 & 19 & 19.6 & 21.4 & 24 & 30.2 \\
\hline & Jul & Ago & Sep & Oct & Nov & Dic \\
\hline $\mathrm{T}_{\text {mínima }}$ & 23.5 & 22.2 & 19.9 & 16.5 & 10.8 & 7.5 \\
\hline $\mathrm{T}_{\text {máxima }}$ & 38.1 & 36 & 34.9 & 35.4 & 29 & 23.7 \\
\hline $\mathrm{T}_{\text {media }}$ & 30.8 & 29.1 & 27.4 & 26 & 19.9 & 15.6 \\
\hline \multicolumn{2}{|c|}{$\begin{array}{l}\text { Promedio } \\
T_{\text {mínima }}=14.2\end{array}$} & \multicolumn{2}{|c|}{$\begin{array}{l}\text { Promedio } \\
\mathbf{T}_{\text {máxima }}=32\end{array}$} & \multicolumn{3}{|c|}{$\begin{array}{l}\text { Promedio } \\
T_{\text {media }}=23.1\end{array}$} \\
\hline
\end{tabular}

Tabla 1 Temperaturas $\left(\mathrm{en}^{\circ} \mathrm{C}\right)$ mínimas, máximas y media registradas en Hermosillo

Fuente: (Servicio Metereológico Nacional, 2017)

Para la localidad de Hermosillo Sonora, se pueden clasificar entonces dos rangos de temperatura en la que pueden trabajar los microorganismos según (Lagrange, 1979); en los meses de noviembre, diciembre, enero, febrero, marzo, abril y mayo, los microorganismos trabajaran en el rango psicrófilo debido a que la temperatura promedio es menor a $\operatorname{los} 25^{\circ} \mathrm{C}$. 
En los meses de junio, julio, agosto, septiembre y octubre, los microorganismos trabajaran en el rango mesófilo (entre 25 y $45^{\circ} \mathrm{C}$ ), según datos de tabla 1. Para la producción psycrophilica, para meses de invierno, los rangos de monitoreo de temperatura en el biodigestor serán los siguientes; temperatura mínima de 4 a $10^{\circ} \mathrm{C}$, temperatura óptima de 15 a $18^{\circ} \mathrm{C}$, temperatura máxima de 20 a $25^{\circ} \mathrm{C}$, ver tabla 2 .

Para la producción mesophilica, en los meses de verano, los rangos de monitoreo de temperatura en el biodigestor serán los siguientes; temperatura mínima de 15 a $20^{\circ} \mathrm{C}$, temperatura óptima de 25 a $35^{\circ} \mathrm{C}$, temperatura máxima de 35 a $45^{\circ} \mathrm{C}$, ver tabla 2 .

\section{pH de operación del biodigestor}

El pH es una medida de la actividad del ion hidrogeno, referente para indicar los niveles de acides y alcalinidad de una sustancia, compuesto, proceso, etc., es por ello que juega un papel de relevante importancia en el proceso de biodigestión. Para los rangos de $\mathrm{pH}$ en el proceso de biodigestión, se tomará como referencia un $\mathrm{pH}$ de 6.5 a 7.5 como óptimo para las bacterias metanogénicas, por debajo de los 6.5 en la escala de $\mathrm{pH}$, las bacterias metanogénicas acetoclastas disminuyen su actividad, y por debajo de un $\mathrm{pH}$ de 5.5 detienen su actividad (Sebastian Nogués, Abián Vicén, Reseau \& García-Galindo, 2010), por debajo de un $\mathrm{pH}$ de 4.5 la actividad microbiana total detiene el proceso (Lema \& Méndez, 1997).

\begin{tabular}{|l|r|r|r|r|}
\hline \multicolumn{1}{|c}{$\begin{array}{c}\text { Fermenta- } \\
\text { ción }\end{array}$} & \multicolumn{1}{c|}{$\begin{array}{c}\mathrm{T} \\
\text { mínima } \\
\left({ }^{\circ} \mathrm{C}\right)\end{array}$} & $\begin{array}{c}\mathrm{T} \\
\text { óptima } \\
\left({ }^{\circ} \mathrm{C}\right)\end{array}$ & $\begin{array}{c}\mathrm{T} \\
\text { máxi- } \\
\text { ma } \\
\left({ }^{\circ} \mathrm{C}\right)\end{array}$ & $\begin{array}{c}\text { Tiempo de } \\
\text { fermenta- } \\
\text { ción (días) }\end{array}$ \\
\hline $\begin{array}{l}\text { Psicrophi- } \\
\text { lica }\end{array}$ & $4-10$ & $15-18$ & $20-25$ & Sobre 100 \\
\hline Mesophi-lica & $15-20$ & $25-35$ & $35-45$ & $30-60$ \\
\hline $\begin{array}{l}\text { Thermophi- } \\
\text { lica }\end{array}$ & $25-45$ & $50-60$ & $75-80$ & $10-15$ \\
\hline
\end{tabular}

Tabla 2 Rangos de temperatura y tiempo de fermentación anaeróbica, adaptado de (Lagrange, 1979)

\section{Tiempo de retención}

El proceso de fermentación del biogás requiere de valores óptimos de materia sólida, este factor dependerá exclusivamente de los rangos de operación de temperatura a los que esté sometido el proceso.
Para el diseño del biodigestor automatizado, se utilizarán dos rangos para el tiempo de fermentación, debido a las extremas temperaturas registradas en Hermosillo. Por lo tanto, para meses de invierno, se estimará un tiempo de fermentación superior a 100 días, y para meses de verano, el rango de operación del proceso de fermentación, estará de 30 a 60 días (Lagrange, 1979). Sin embargo, se tomarán en consideración los porcentajes de metano emitidos durante los rangos de fermentación, esto quiere decir, que si la curva critica de producción decrece antes del tiempo estimado, se alimentará al reactor con nueva materia orgánica.

\section{Tipo de sustrato seleccionado; naturaleza y composición bioquímica}

Los residuos empleados para los procesos de fermentación metanogénica, independientemente cual sea su origen, juegan un papel importante en la cantidad y calidad de la producción de biogás. Se pueden utilizar diversas materias primas, en las que destacan las de origen vegetal y animal derivadas de actividades agrícolas y ganaderas. Se debe de considerar que las características bioquímicas de los residuos seleccionados para el proceso de producción de biogás, permiten en todo momento un óptimo desarrollo y actividad en los microbios presentes, sobre todo por las concentraciones de carbono y nitrógeno, aunque también requiere de agentes como sales minerales, que comúnmente se encuentran en materia orgánica de origen vegetal y animal.

Para efectos de experimentación, en el diseño del biodigestor, se utiliza como materia prima residuos de origen vegetal, específicamente hortalizas del grupo $\mathrm{C}$, que contienen más del $10 \%$ de hidratos de carbono. La selección de la hortaliza será la papa blanca, debido a que presenta una concentración química de $30 \% \mathrm{C}, 0.34 \% \mathrm{~N}, 0.16 \%$ de $\mathrm{P}_{2} \mathrm{O}_{5}$, $0.58 \%$ de $\mathrm{K}_{2} \mathrm{O}$ y $0.64 \%$ de $\mathrm{CaO}$ (ver tabla 3 ). Esta condición la hace una materia prima con gran potencial en la producción de biogás, ya que la relación de consumo de carbono por parte de las bacterias es 30 veces más que la del nitrógeno (Varnero \& Arellano, 1990). 
La clasificación del sustrato, es de clase 1, perteneciente a los sustratos sólidos, cuyas características cualitativas son; $>20 \%$ solidos totales, con un 40 a $70 \%$ de fracción orgánica (ver tabla 4).

\section{Niveles de sólidos totales y sólidos volátiles}

Los sólidos totales están compuestos por una fracción de agua y una sólida. Para el diseño del biodigestor se tomará como referencia a Carrillo, (2003), que establece que experimentalmente se ha demostrado que una carga entre 7 y 9 de sólidos totales es considerada como óptima.

\begin{tabular}{|c|c|c|c|c|c|c|}
\hline $\begin{array}{l}\text { Materia } \\
\text { prima }\end{array}$ & $\% \mathrm{C}$ & $\% \mathbf{N}$ & $\begin{array}{c}\% \\
\mathrm{P}_{2} \mathrm{O}_{5}\end{array}$ & $\begin{array}{c}\% \\
\mathrm{~K}_{2} \mathrm{O}\end{array}$ & $\begin{array}{c}\% \\
\mathrm{CaO}\end{array}$ & $\begin{array}{c}\% \\
\text { MgO }\end{array}$ \\
\hline \multicolumn{7}{|l|}{ Excretas } \\
\hline Bovino & \begin{tabular}{|ll}
17.4 & - \\
40.6 &
\end{tabular} & $\begin{array}{ll}0.3 \\
2.0\end{array}$ & \begin{tabular}{|ll}
0.1 & - \\
1.5 &
\end{tabular} & 0.10 & 0.35 & 0.13 \\
\hline Porcino & $\begin{array}{ll}17.4 & - \\
46.0 & \end{array}$ & $\begin{array}{ll}1.1 \\
2.5\end{array}-$ & \begin{tabular}{|ll}
0.4 & - \\
4.6 &
\end{tabular} & 0.30 & 0.09 & 0.10 \\
\hline Caprino & $\begin{array}{|ll|}35.0 & - \\
50.0 & \\
\end{array}$ & $\begin{array}{ll}1.0 \\
2.0\end{array}$ & $\begin{array}{|ll|}0.2 & - \\
1.5 & \\
\end{array}$ & 2.30 & & \\
\hline Equino & \begin{tabular}{|ll}
35.0 & - \\
52.0 & \\
\end{tabular} & $\begin{array}{ll}0.3 \\
0.8\end{array}$ & \begin{tabular}{|ll}
0.4 & - \\
1.6 & \\
\end{tabular} & 0.35 & 0.15 & 0.12 \\
\hline \multicolumn{7}{|l|}{ Mezclas } \\
\hline $\begin{array}{ll}\begin{array}{l}\text { Porcino } \\
\text { paja }\end{array} & + \\
\end{array}$ & $\begin{array}{|ll|}20.0 & - \\
22.0 & \\
\end{array}$ & $\begin{array}{ll}0.3 & - \\
0.5 & \end{array}$ & 0.24 & 0.63 & 0.20 & \\
\hline $\begin{array}{l}\text { Bovino } \\
\text { paja }\end{array}$ & \begin{tabular}{|ll}
44.0 & - \\
46.0 & \\
\end{tabular} & $\begin{array}{ll}0.3 \\
0.5\end{array}$ & 0.79 & 1.55 & 0.30 & \\
\hline \multicolumn{7}{|l|}{ Rastrojos } \\
\hline Paja de trigo & \begin{tabular}{|ll}
16.0 & - \\
46.0 & \\
\end{tabular} & 0.53 & 0.70 & 0.40 & 0.26 & 0.16 \\
\hline Papas & 30.0 & 0.34 & 0.16 & 0.58 & 0.64 & \\
\hline
\end{tabular}

Tabla 3 Rango de niveles de nutrientes en diversos residuos de origen animal y vegetal, adaptado de (Varnero \& Arellano, 1990).

\section{Agitación de la mezcla}

Debido a que la agitación busca aumentar la producción de biogás, ya que beneficia a múltiples factores como la distribución uniforme de la temperatura, evita la generación de costra, hace más uniforme la densidad bacteriana y además evita "huecos" sin actividad biológica, por mencionar algunos (Varnero Moreno, 2011). Según Magaña, Torres, Martínez, Sandoval \& Hernández, (2011), establecen que el consorcio microbiano de la etapa metanogénica manifiesta una gran sensibilidad a los cambios de agitación, y realizan su función con mejores rendimientos a $160 \mathrm{rpm}$ (revoluciones por minuto). La alta agitación propicia que los sustratos sean más solubles en el medio y, por consiguiente, los microorganismos tengan mayor afinidad a la materia orgánica.

\begin{tabular}{|c|c|c|c|}
\hline $\begin{array}{l}\text { Caracterís- } \\
\text { ticas }\end{array}$ & $\begin{array}{c}\text { Clas } \\
\text { e }\end{array}$ & $\begin{array}{l}\text { Tipo de } \\
\text { sustrato }\end{array}$ & $\begin{array}{l}\text { Características } \\
\text { cuantitativas }\end{array}$ \\
\hline \multirow[b]{2}{*}{ Sólidos } & \multirow[b]{2}{*}{1} & \multirow{2}{*}{$\begin{array}{l}\text { Basura } \\
\text { doméstica } \\
\text { Estiércol sólido } \\
\text { Restos de } \\
\text { cosecha }\end{array}$} & $\begin{array}{l}>20 \% \text { de sólidos totales } \\
\text { (ST) }\end{array}$ \\
\hline & & & $\begin{array}{l}40-70 \% \text { de fracción } \\
\text { orgánica }\end{array}$ \\
\hline $\begin{array}{l}\text { Lodo } \\
\text { altamente } \\
\text { contaminado, } \\
\text { alta viscosidad }\end{array}$ & 2 & Heces animales & $\begin{array}{l}100-150 \mathrm{~g} / 1 \mathrm{DQO}, 5 \%- \\
10 \%(\mathrm{ST}) \text { y } 4 \%-8 \% \mathrm{SV}\end{array}$ \\
\hline $\begin{array}{l}\text { Fluidos con } \\
\text { alto contenido } \\
\text { de solidos } \\
\text { suspendidos } \\
\text { (SS) } \\
\end{array}$ & 3 & $\begin{array}{l}\text { Heces animales } \\
\text { de cría y aguas } \\
\text { residuales de } \\
\text { mataderos }\end{array}$ & $\begin{array}{l}\text { 3-17 g/l DQO (Demanda } \\
\text { química de oxigeno) y 1-2 } \\
\text { g/l SS }\end{array}$ \\
\hline $\begin{array}{l}\text { Fluidos muy } \\
\text { contaminados, } \\
\text { sólidos en } \\
\text { suspensión }\end{array}$ & 4 & $\begin{array}{l}\text { Aguas } \\
\text { residuales de } \\
\text { agroindustrias } \\
\text { y aguas negras }\end{array}$ & 4-500 g/l DQO \\
\hline
\end{tabular}

Tabla 4 Clasificación de sustratos para la biodigestión, adaptado de (Esguerra, 1989)

\section{Humedad}

En el proceso de producción de biogás se requiere, que dentro del biodigestor se mantenga un alto índice de humedad, entre un 80 y $90 \%$, sin embargo, los altos índices de humedad generan que el metano producido sea un gas naturalmente húmedo, por lo que puede dañar partes metálicas del reactor o las cañerías de conducción del gas, además los índices de humedad presentes, disminuyen el contenido calórico de la muestra producidas.

\section{Metano}

El metano es un gas incoloro e inodoro, su punto de ebullición es a los $-160^{\circ} \mathrm{C}$ y su punto de fusión a los $-184{ }^{\circ} \mathrm{C}$, es el constituyente principal del gas natural y en combinación con oxígeno o aire forman una mezcla explosiva (Hopp, 1994).

\begin{tabular}{|c|c|c|c|}
\hline $\begin{array}{l}\text { Variable a } \\
\text { sensar }\end{array}$ & $\begin{array}{c}\text { Nombre del } \\
\text { sensor }\end{array}$ & $\begin{array}{c}\text { Descripción del } \\
\text { sensor }\end{array}$ & Imagen \\
\hline Temperatura & LM35 & $\begin{array}{l}\text { Los sensores } \\
\text { LM35 son } \\
\text { dispositivos } \\
\text { digitales precisos } \\
\text { para medición de } \\
\text { temperatura, que } \\
\text { funcionan con una } \\
\text { tensión de salida } \\
\text { lineal } \\
\text { proporcional a la } \\
\text { temperatura en } \\
\text { grados } \\
\text { centígrados. Este } \\
\text { tipo de sensor } \\
\text { presenta la ventaja } \\
\text { de que no necesita } \\
\text { ningún tipo de } \\
\text { calibración. } \\
\text { sensor Ll LM35 } \\
\text { tiene un consumo } \\
\text { de } 60 \mu \mathrm{V} \text { y opera } \\
\text { en rangos del } \\
\text { voltaje de } 4 \text { a } 30 \\
\text { V. }\end{array}$ & 11 \\
\hline
\end{tabular}

MONTIJO-VALENZUELA, Eliel Eduardo, RAMÍREZ-TORRES, Flor, RIVERA-LANDAVERDE, Rodolfo Ulises y RAMÍREZCORONEL, Fernando Joaquín. Diseño y monitoreo en tiempo real de un biodigestor, aplicado a las condiciones ambientales de Hermosillo. Revista de Ingeniería Innovativa. 2019 


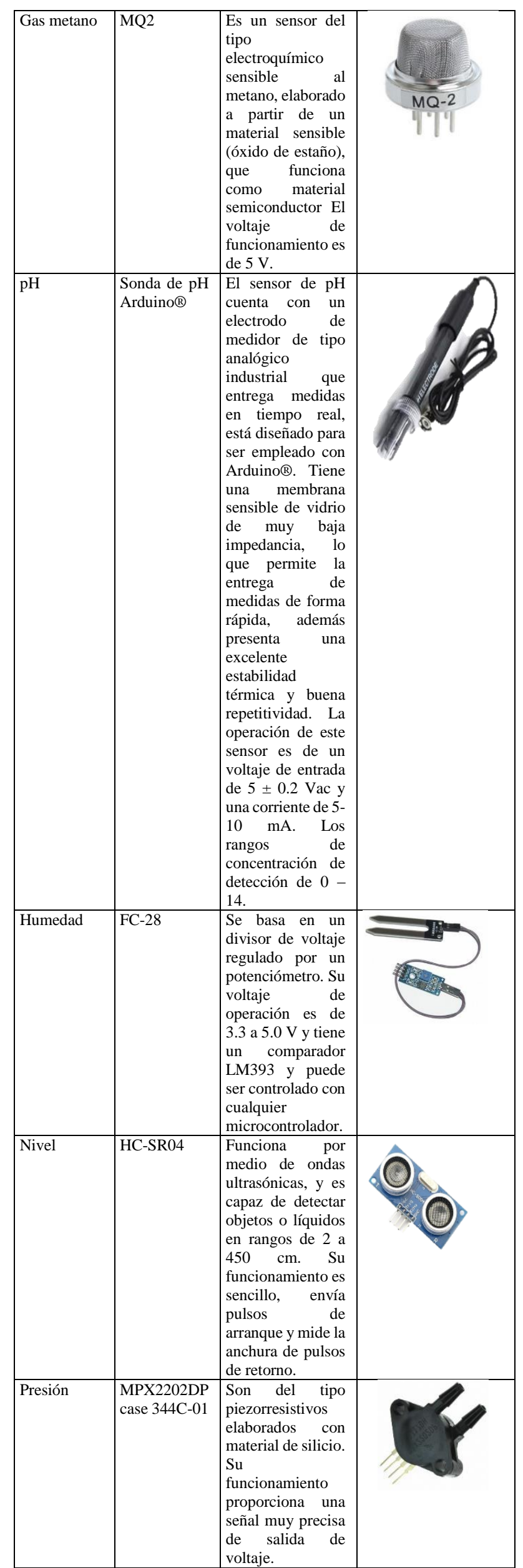

Tabla 5 Selección de los instrumentos de medición para el sistema
A nivel industrial, el metano es utilizado como materia prima en la elaboración de múltiples productos sintéticos, pero su principal aplicación a nivel mundial en los últimos años, ha sido como fuente energética alternativa a pequeña escala, generado a partir de residuos orgánicos agrícolas.

El biogás producido por métodos de fermentación, está compuesto por un 55 a 70\% de metano, 30 a $45 \%$ de dióxido de carbono y $3 \%$ de otros gases, con un poder calorífico de $5500 \mathrm{Kcal} / \mathrm{m}^{3}$ (Melendi, 2015) Para el diseño del biodigestor se utilizó un sensor de metano, el cual envía a un ordenador las partes por millón producidas de este gas en el proceso de biodigestión.

\section{Muestra y caracterización de la investigación}

Para el diseño de esta investigación se utilizó el método deductivo, mediante la recopilación de información principalmente de libros, artículos de divulgación científica, manuales y tesis de grado, con el objeto de tener bases científicas y analíticas sobre la generación de biogás por medio de biodigestión anaerobia. El método deductivo, fue complementado con el método inductivo, cuyo objeto será comprobar las hipótesis respecto al desarrollo y simulación del sistema de generación de biogás automatizado, basándonos en los criterios y variables obtenidos en el método deductivo.

Para las conclusiones finales, se utilizará el método sintético, aplicado a esta investigación con la finalidad de reagrupar cada una de las variables recopiladas y los factores que intervienen en ellas para la producción de biogás, de este modo se realizará un análisis generalizado, que permitirá la discusión de resultados con bases científicas. $\mathrm{La}$ investigación será de carácter descriptivo, ya que se darán a conocer las variables que afectan el proceso de biodigestión y los factores que alteran dicho proceso, y está orientada a la comprobación, debido a que se verificara con los objetivos planteados en la investigación. Se utilizaron como muestra 10 litros de papa blanca (Solanum tuberosum) molida, una especie de planta herbácea del genero Solanum originaria de Sudamérica, para el experimento realizado. Los experimentos se realizaron en Hermosillo Sonora. 


\section{Instrumentos de medición}

En los procesos y sistemas industriales con cadena de retroalimentación, es de imperante relevancia realizar un control de lazo cerrado, que ayudan a corregir de una forma rápida todos los errores presentes o condiciones que estén fuera de parámetros. Estas cadenas de retroalimentación, necesitan para su funcionamiento, elementos que capten las diversas magnitudes que se pretenden "monitorear", por medio de sensores y circuitos de interfaz. En Balcells \& Romeral, (1997), se define a los sensores como "un dispositivo capaz de convertir el valor de una magnitud física en una señal eléctrica codificada, ya sea en forma analógica o digital", de este modo, lo sistemas de sensado son entonces elementos de captación, diseñados para tomar información de magnitudes del entorno y transformarlas en otro tipo de magnitud, la cual seamos capaces de medir y manipular.

\section{Resultados}

En este apartado, se muestran los resultados obtenidos en las fases de simulación y experimentación, que incluyen; 3.1) el diseño y ensamblaje de los componentes integrales del biodigestor en software especializado (Solidworks), 3.2) simulación de los componentes electrónicos (sensores) y de control en software Proteus 8.0,3.3) calibración e integración de los componentes electrónicos con pruebas de laboratorio, 3.4) pruebas de interfaz y registro de variables sensadas con software Visual Studio, y 3.5) experimentación y pruebas de campo en la ciudad de Hermosillo.

\section{Diseño y ensamblaje del sistema en software}

El diseño mecánico integra una serie de componentes, que incluyen un biorreactor, un agitador, una armadura, un eje y un motor. El biorreactor es de forma cilíndrica y de material plástico, tiene una altura de $0.75 \mathrm{~m}$ y un diámetro de $0.50 \mathrm{~m}$. En la parte superior tiene un tubo alimentador con un diámetro de $.15 \mathrm{~m}$ y una inclinación de $45^{\circ}$ respecto a la horizontal, con la finalidad de que el material suministrado al interior del biorreactor, se deslice de una forma eficiente aprovechando los efectos de la gravedad terrestre.
Este mismo orificio, servirá como el escape de los gases producidos por los efectos de la biodigestión en la materia orgánica. En la parte central de la cara superior, el biorreactor tiene un orificio de radio $0.05 \mathrm{~m}$, por el cual concéntricamente se insertará un eje cuya función es sostener las hélices de agitación para mover la materia dentro del biorreactor. Por la parte inferior el biorreactor presenta un orificio de $0.15 \mathrm{~m}$, por donde será liberada la biomasa una vez que se cumpla todo su proceso de producción. El diseño del biorreactor se muestra en la figura 1.

El agitador está diseñado en doble propela (dos hélices conectadas al eje). El tipo de agitador es de turbina para movimientos de flujo radial (ver figura 2). La armadura (ver figura 3) está elaborada de acero y cumple la función de mantener de forma concéntrica el biorreactor, evitando su deformación por un incremento súbito de la presión dentro del recipiente. El eje de agitación (ver figura 4) está diseñado con dos secciones para acople soldado de hélices.

El material del eje es de acero y presenta una longitud de $1.83 \mathrm{~m}$, con dos diferenciales de diámetro, $0.08 \mathrm{~m}$ y $0.12 \mathrm{~m}$ a lo largo de la sección longitudinal. El motor (ver figura 5) seleccionado para la agitación es eléctrico con una potencia de 0.5 caballos de fuerza. La función del motor es mover al eje para propiciar el movimiento radial por medio de las hélices. El ensamblaje de los componentes mecánicos del biodigestor se puede observar en la figura 6 .

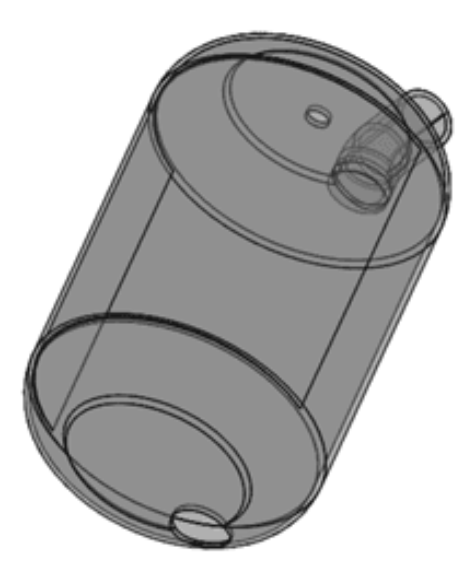

Figura 1 Diseño del biorreactor, vista isométrica 


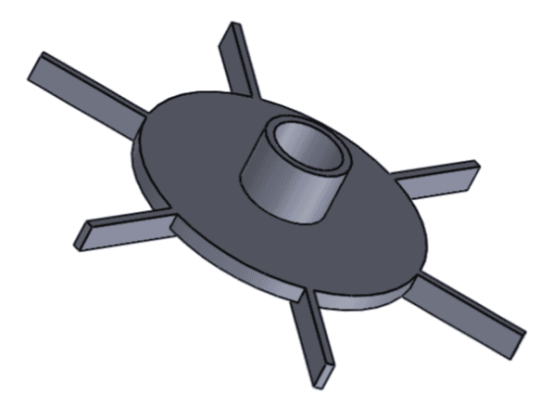

Figura 2 Diseño del agitador

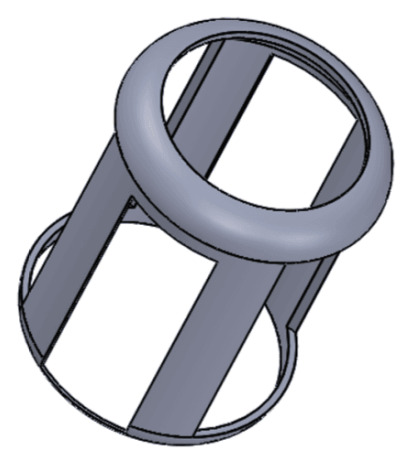

Figura 3 Diseño de la armadura.

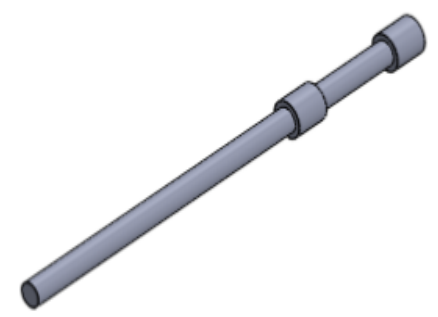

Figura 4 Diseño del eje

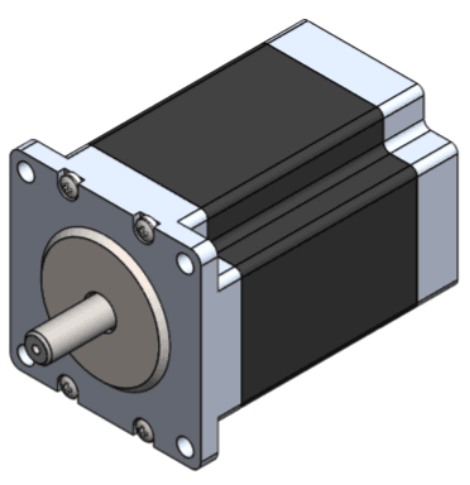

Figura 5 Diseño del motor

\section{Diseño y simulación electrónica}

El diseño y simulación electrónica se realizó con tres sensores distintos; el sensor de temperatura LM35, el sensor de nivel HC-SR04 y el sensor de $\mathrm{pH}$.
Para la simulación se descargó la librería de Arduino® compatible con Proteus 8.0, esto facilita las conexiones y la simplicidad del diseño de los circuitos. Para el sensado virtual de la temperatura (figura 7) se utilizaron los siguientes componentes: un indicador LED de color rojo y un indicador LED de color verde. La función del LED rojo es indicar que la temperatura pasó el límite superior indicado en la programación del Arduino® (virtualmente), por otro lado, la función del LED verde es indicar cuando la temperatura pasó el límite inferior. Se integra el componente de sensado de temperatura LM35 y una terminal virtual que interpreta los valores numéricos al incrementar o reducir el valor del sensor LM35 desde el circuito de simulación.

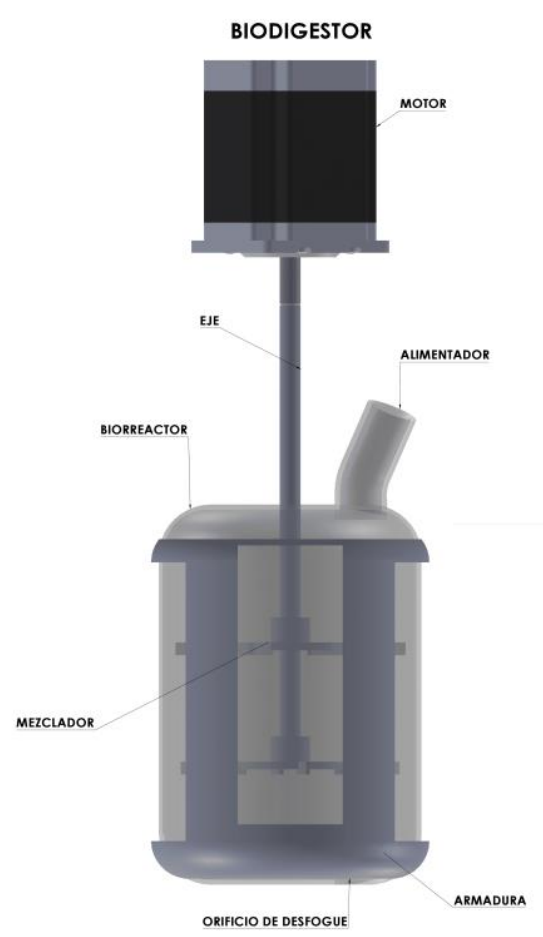

Figura 6 Ensamble mecánico del biodigestor

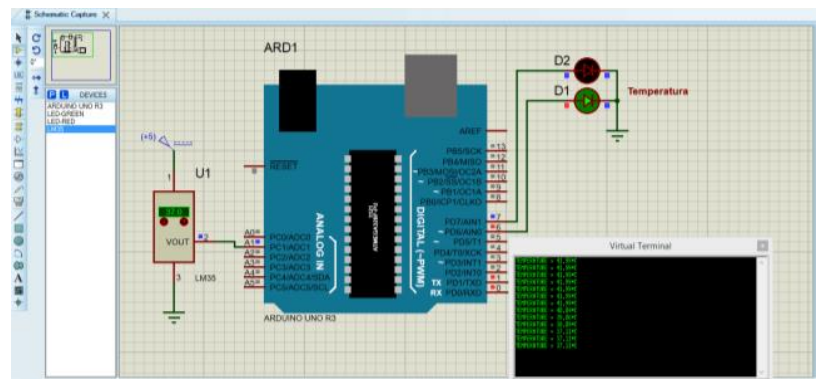

Figura 7 Sensado de temperatura con LM35 desde simulador Proteus 8.0 
Para el sensado virtual del nivel con el sensor HC-SR04, se descargó la librería del sensor ultrasónico, el cual se conectó directamente al simulador de Arduino® y una pantalla LCD (ver figura 8).

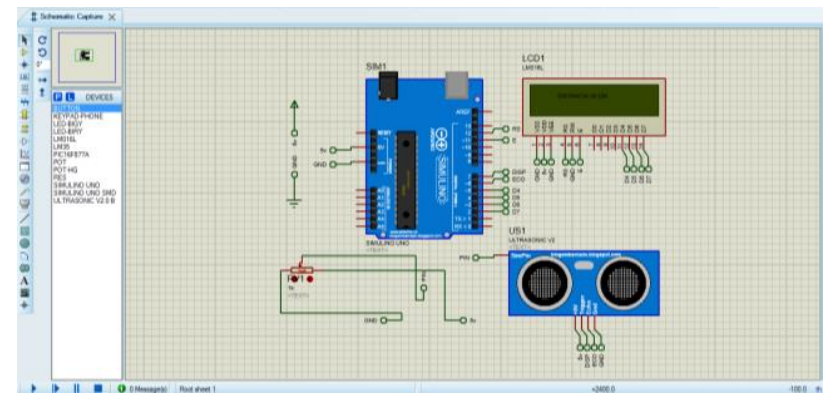

Figura 8 Sensado de nivel con HC-SR04 desde simulador Proteus 8.0

Para el sensado virtual del pH (ver figura 9), se utilizaron los siguientes componentes virtuales; un botón, un LED indicador amarillo y cinco resistencias de $1000 \mathrm{k} \Omega$. La terminal virtual indica los valores de $\mathrm{pH}$ al aumentar o disminuir la resistencia con el potenciómetro.

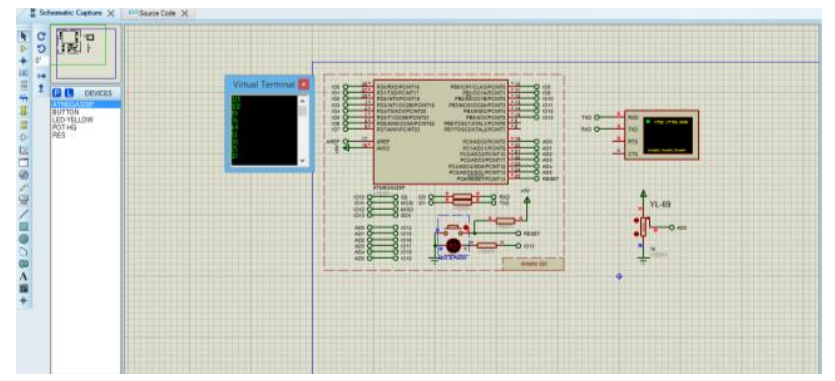

Figura 9 Sensado de $\mathrm{pH}$ desde simulador Proteus 8.0

\section{Calibración e integración de los componentes electrónicos con pruebas de laboratorio}

Para realizar la conexión de los sensores primeramente se analizaron sus hoja de especificaciones, posteriormente se calibraron de la siguiente manera. Para el sensor de temperatura LM35, se prepararon dos experimentos. En el primer experimento se utilizó agua fría y se midió con termómetro de mercurio, inmediatamente se corroboró la medición con sensor LM35. Posteriormente en el experimento 2 se calentó el agua y se procedió a medir la temperatura con termómetro de mercurio y con sensor LM35. Para ambos casos las mediciones de ambos instrumentos fueron iguales.
Para el sensor de nivel HC-SR04, se utilizó como instrumento de comparación un flexómetro, que sirvió como base en la calibración. Se realizaron cinco medidas distintas con el flexómetro, a las siguientes alturas: 5, 30, 45, 120 y $150 \mathrm{~cm}$, posteriormente se realizaron las medidas con el sensor ultrasónico de nivel, obteniendo las siguientes mediciones: 5.10, 30.22, 45, 120.10 y 150.20 $\mathrm{cm}$, teniendo una precisión con un error mínimo. Para el sensor de $\mathrm{pH}$ se utilizó como referencia un phmetro digital de la marca TPM LT serie YK21ph y tres sustancias con $\mathrm{pH}$ conocido para la calibración de este mismo sensor digital, los valores de $\mathrm{pH}$ de las sustancias fueron 3, 7 y 9 .

El phmetro digital y las sustancias de calibración, fueron proporcionados por el laboratorio de química del Instituto Tecnológico de Hermosillo. La sonda de $\mathrm{pH}$ implementada para el proyecto, fue probada en las tres sustancias, arrojando los valores de 2.9 a 3 para la sustancia 1, 7.1 la sustancia 2 y 8.9 a 9 la sustancia 3. Para la calibración del sensor de humedad se utilizó el siguiente procedimiento: se tomó como valor de $100 \%$ el valor de voltaje arrojado por el sensor sumergido totalmente en algodón saturado con agua, y $0 \%$ el voltaje arrojado por el sensor sumergido totalmente en polvo desecado. Para la calibración del sensor de presión, se conectó una fuente neumática (compresor) con un valor conocido de presión, arrojado por un indicador de la marca FESTO (figura 10), esta calibración se realizó en el laboratorio de ingeniería mecatrónica del Instituto Tecnológico de Hermosillo.

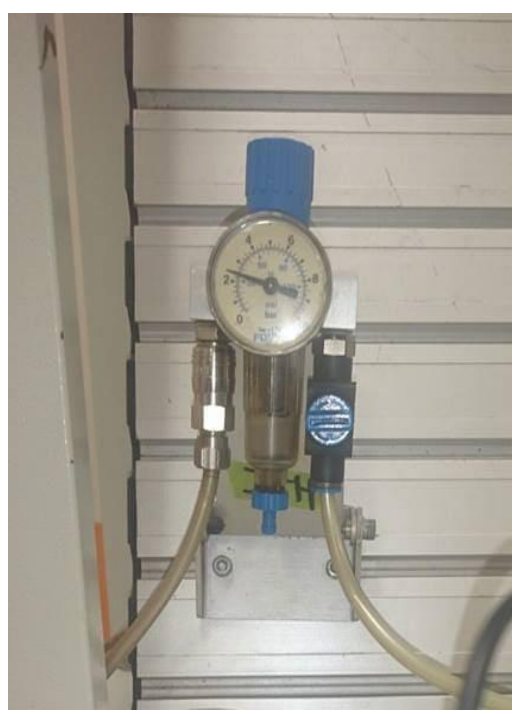

Figura 10 Calibración de sensor de presión mediante una fuente neumática (compresor) con valor conocido de presión mediante indicador marca FESTO 
Una vez calibrados los sensores, se armó el circuito integral que comprende el sistema de sensado integrado a la placa de Arduino®. En este apartado se muestran las conexiones esquemáticas independientes de cada uno de los sensores; sensor LM35 (ver figura 11), sensor HC-SR04 (ver figura 12), sensor MQ2 (ver figura 13), sensor FC-28 (ver figura 14) y sensor MPX2202DP case 344C-01 (ver figura 15) y la conexión final integrando todos ellos a la placa de Arduino® (figura 16). La distribución de los componentes en el diseño final del biodigestor, se muestra en la figura 17.

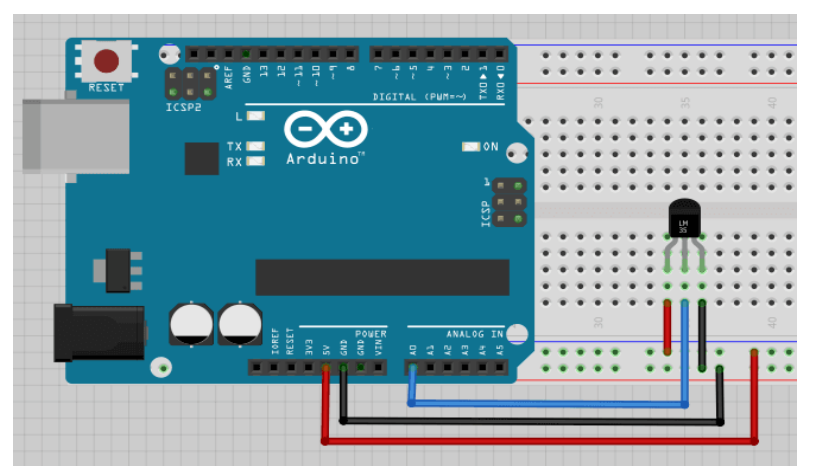

Figura 11 Conexión esquemática del sensor LM35 a placa Arduino ${ }^{\circledR}$

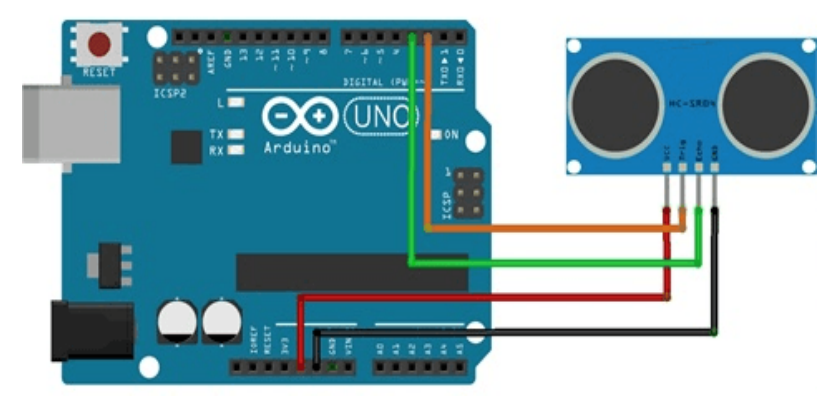

Figura 12 Conexión esquemática del sensor HC-SR04 a placa Arduino®

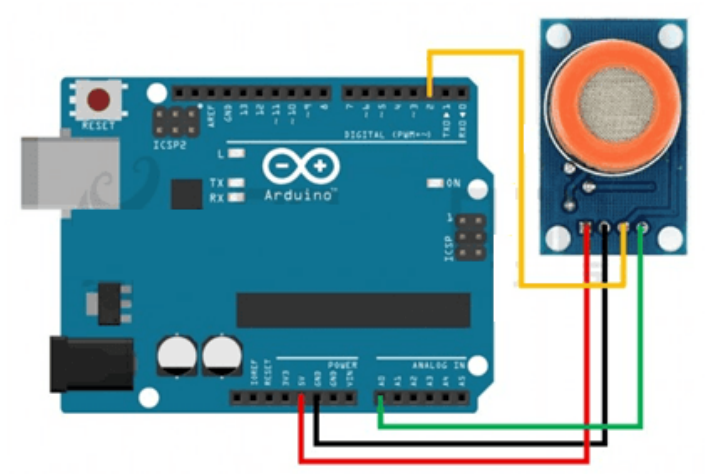

Figura 13 Conexión esquemática del sensor MQ2 a placa Arduino®

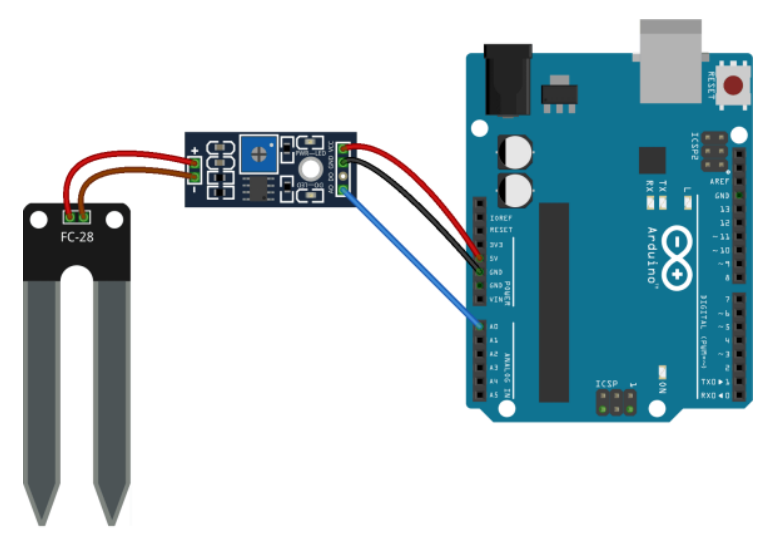

Figura 14 Conexión esquemática del sensor de humedad FC-28 a placa Arduino ${ }^{\circledR}$

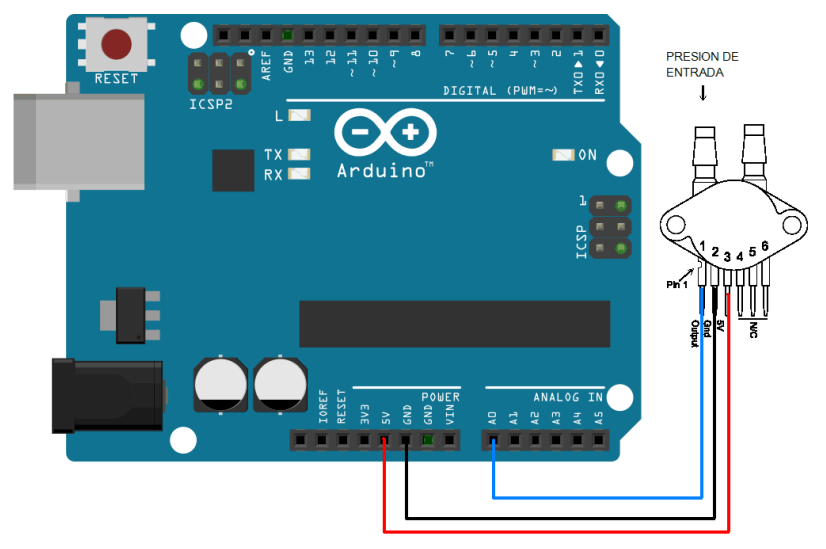

Figura 15 Conexión esquemática del sensor de presión MPX2202DP case 344C-01 a placa Arduino®

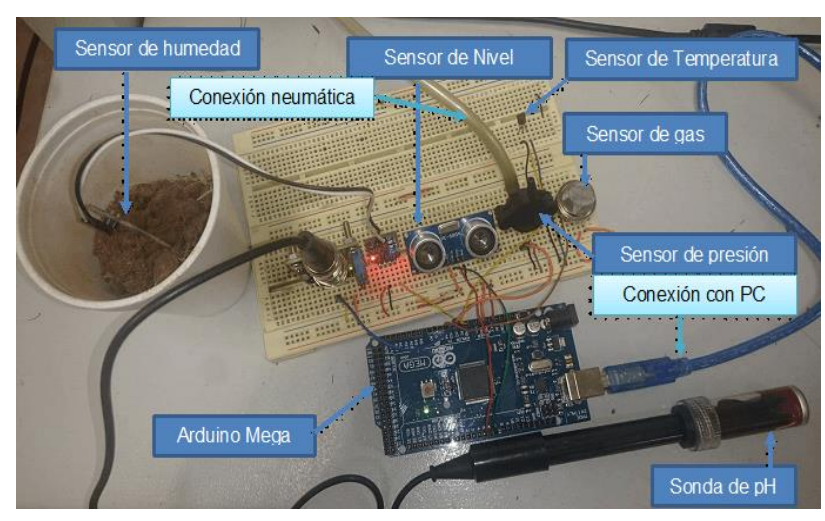

Figura 16 Conexión física integral de los sensores correctamente montados a la placa Arduino® 


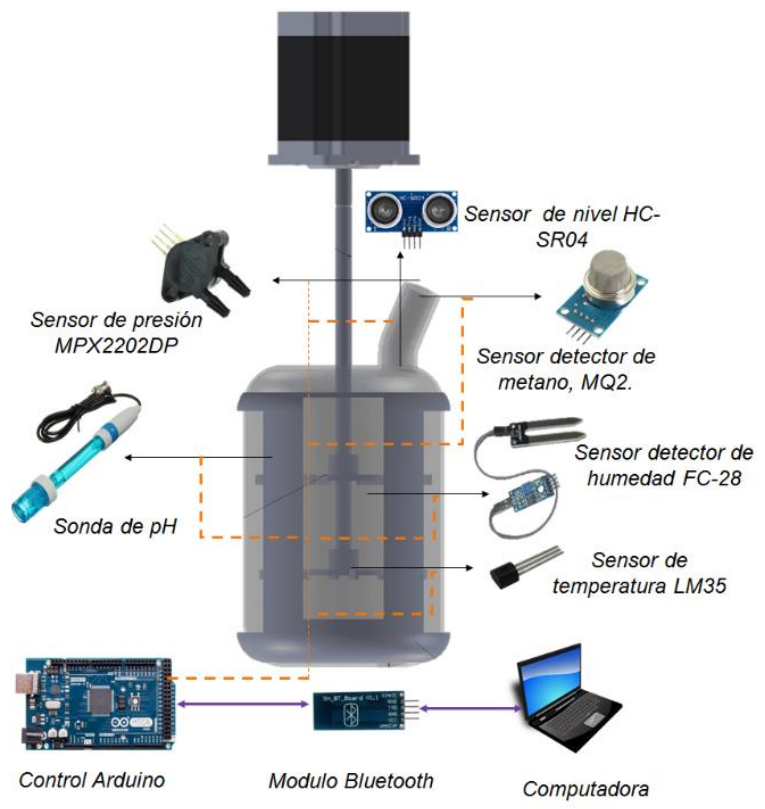

Figura 17 Distribución de los componentes en el diseño final

\section{Pruebas de interfaz y registro de variables sensadas con software Visual Studio}

La lectura de los sensores se procesa desde la placa de Arduino®, por medio de salidas digitales, y se visualiza en una interfaz desde la computadora por medio del software Visual Studio de Microsoft (figura 18). En la figura 19, se muestra la primera prueba del sistema de sensado.

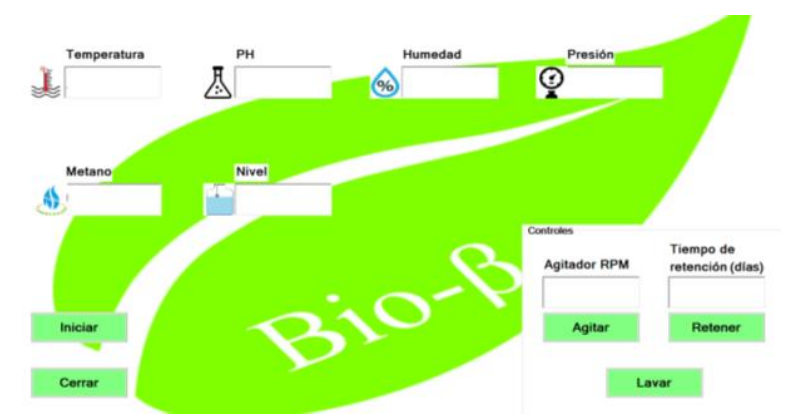

Figura 18 Interfaz de lectura de sensores y control de actuadores con software Visual Studio

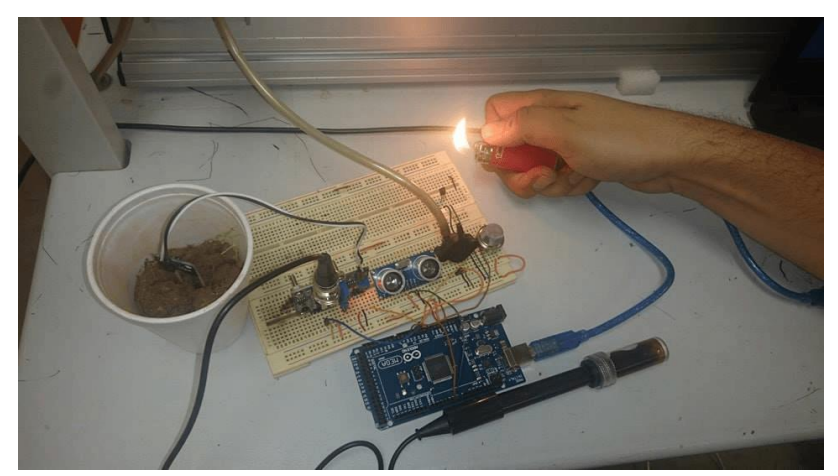

Figura 19 Prueba 1 del sistema de sensado.
Dentro del lodo se clavó el sensor de humedad. En la misma prueba se acercó flama directa al sensor de temperatura y se le adicionó al sensor de $\mathrm{pH}$ una mezcla con acidez de 3.4. La presión suministrada al sensor MPX2202DP case 344C-01 según el indicador, fue de $210 \mathrm{kPa}$. La distancia del sensor de nivel, estuvo referenciada al techo del laboratorio de mecatrónica. Los resultados de la lectura se pueden observar en la figura 20 , en donde se muestra un $97 \%$ de humedad, una temperatura de $70{ }^{\circ} \mathrm{C}$, un nivel de $285 \mathrm{~cm}$, presión de 215 $\mathrm{kPa}$, detección de gas a 0 ppm, y un pH de 3.39, todos los valores correspondientes con las variables de entrada.

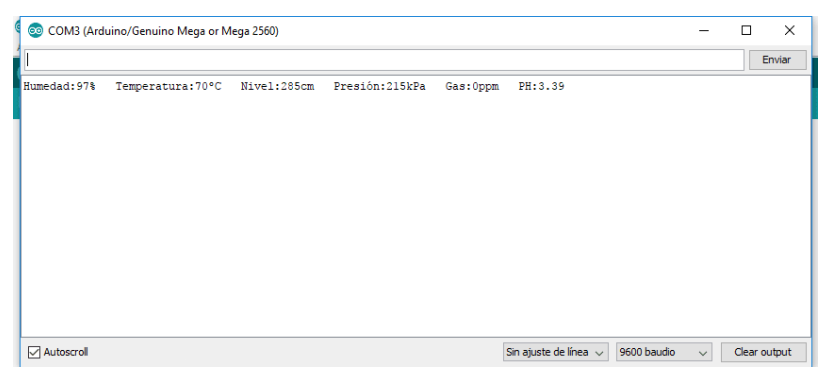

Figura 20 Resultados de lectura de prueba 1

En la prueba 2 (figura 21) cambiaron las siguientes condiciones respecto a la prueba 1 . Se retiró la flama del sensor LM35 y se suministró gas directamente al sensor MQ2 por medio de un encendedor.

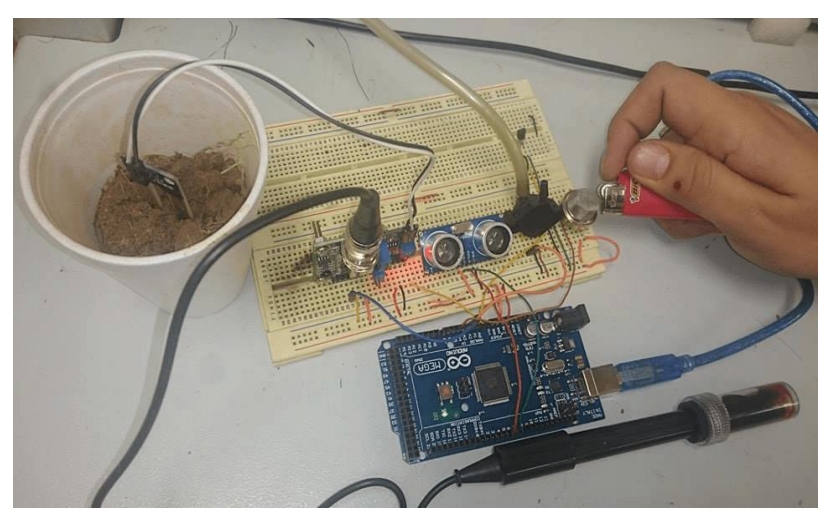

Figura 21 Prueba 2 del sistema de sensado

Los resultados de la lectura se pueden observar en la figura 22 , en donde se muestra un $97 \%$ de humedad, una temperatura de $26{ }^{\circ} \mathrm{C}$ (correspondiente a la del ambiente de la sala de trabajo), un nivel de $285 \mathrm{~cm}$, presión de $215 \mathrm{kPa}$, detección de gas a 668 ppm, y un pH de 3.39. 


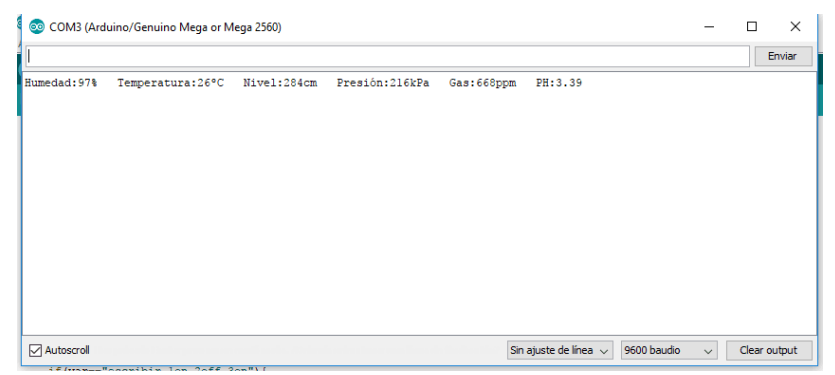

Figura 22 Resultados de lectura de prueba 2.

\section{Experimentación y pruebas de campo en la ciudad de Hermosillo}

En la figura 23 se muestran los valores de lectura de los sensores desde la interfaz de Visual Studio, en el proceso inicial de biodigestión en campo (día 1), teniendo los siguientes valores: temperatura equivalente a $25^{\circ} \mathrm{C}$, el $\mathrm{pH}$ de la patata triturada es de 6.3, la humedad de la mezcla es de $85 \%$ y la presión inicial es de $0 \mathrm{kPa}$ y la producción inicial de gas es también de 0 ppm, la altura del volumen (espacio vacío entre el sensor y la mezcla) dentro del recipiente, corresponde a la medición del nivel, con una medida del $28 \mathrm{~cm}$. El agitador puede ser accionado a $160 \mathrm{rpm}$ y el tiempo de retención de la mezcla es de 24 días, pudiendo ser liberada de forma manual presionando el botón "lavar". El botón "cerrar" sirve como un paro de emergencias ante cualquier inconveniente o como una forma de detener el proceso. El tiempo de retención puede ser cambiado a cualquier valor entero (días). Las revoluciones del agitador también pueden cambiarse manualmente a un valor entre 1 y 160.

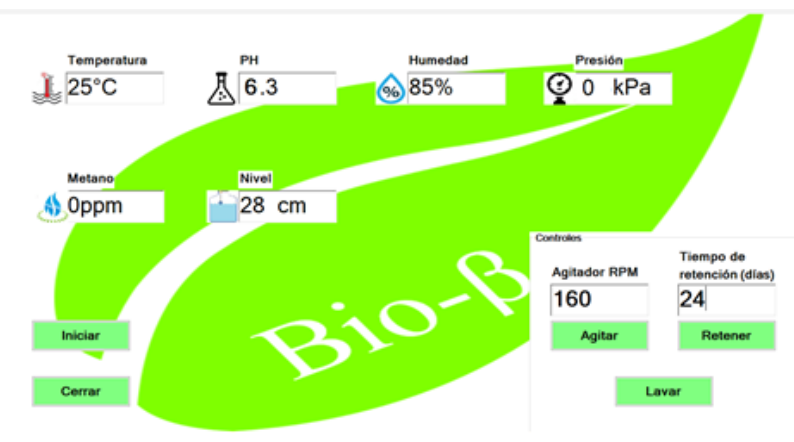

Figura 23 Resultados iniciales del proceso de biodigestión en campo

En la figura 24 se muestran los valores de lectura de los sensores desde la interfaz de Visual Studio, con una duración de 12 días del proceso de biodigestión.
Los resultados fueron los siguientes: temperatura $34{ }^{\circ} \mathrm{C}$, el $\mathrm{pH}$ disminuyó a 6.5 , también hubo un decremento en la humedad, marcando $57 \%$, la presión pasó de 0 a $2 \mathrm{kPa}$, con una lectura de $976 \mathrm{ppm}$ y el nivel tuvo un decremento de $7 \mathrm{~cm}$ respecto a las condiciones iniciales.

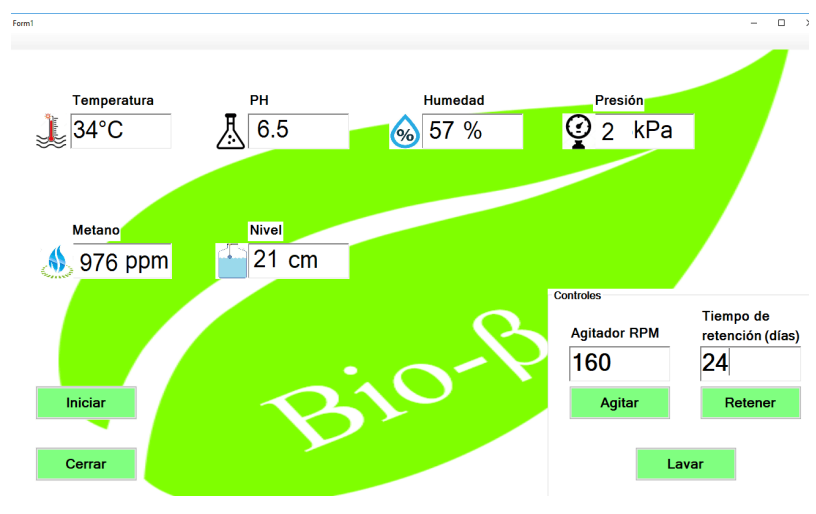

Figura 24 Resultados del proceso de biodigestión en campo a los 12 días

En la figura 25 se muestra un registro con una serie de lecturas de los sensores desde la aplicación de Arduino®.

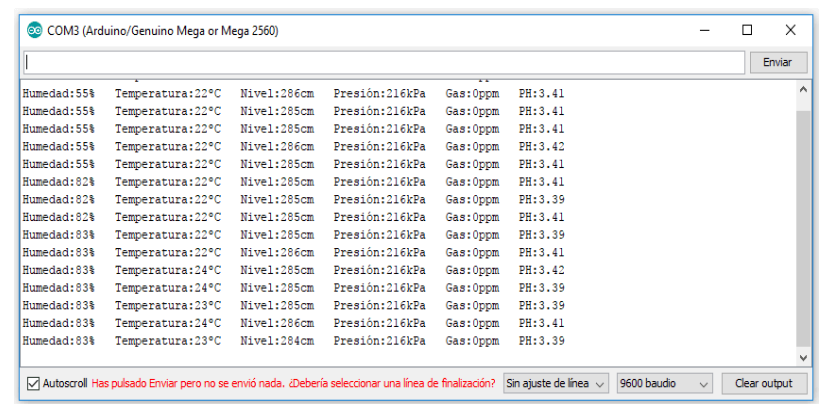

Figura 25 Registro de lecturas de sensores en tiempo real

\section{Análisis de resultados}

Con base al experimento realizado en campo, se observó del día 1 al 12 una disminución del pH de la mezcla, de un 6.3 inicial, muy similar al $\mathrm{pH}$ promedio establecido por Wageningen University and Pontificia Universidad Católica de Valparaíso, (2017), de 6.1, a un 4.1 al día 12, correspondiente a la etapa 2 del proceso de biodigestion, denominada acidogénica, en donde se forman los ácidos, y también la etapa metanogénica en donde se forman los gases, principalmente metano (Campos, Elías \& Floats, 2012). 
En el experimento se monitorearon los principales factores físico químicos que afectan la producción del biogás, independientemente de la materia prima seleccionada, siendo estos; la temperatura, la carga volumétrica, el tiempo de retención y los niveles de acidez y alcalinidad según (Rivas Solano, Faith Vargas \& Guillén Watson, 2010), (Varnero Moreno, 2011) y (Gutiérrez García et al., 2012), además de examinar estos factores en tiempo real, ante la susceptibilidad de los microorganismos a los diferentes cambios ambientales (Rivas Solano, Faith Vargas \& Guillén Watson, 2010). Se observó también que el proceso de producción de biogás por medio de biodigestión anaerobia, aplicado a la ciudad de Hermosillo, puede ser de dos tipos; en verano (mayo a octubre), cuando la temperatura es mayor a los $25^{\circ} \mathrm{C}$, la producción es del tipo mesophilica, y en invierno (noviembre a abril), cuando la temperatura es menor a $25{ }^{\circ} \mathrm{C}$, la producción es del tipo psycrophilica (Rivas Solano, Faith Vargas \& Guillén Watson, 2010).

Se observó que el incremento de la temperatura en los días de prueba tiene efectos positivos en la producción de gas, ya que los picos más altos medidos en ppm registrados en los 12 días de producción, coincidían con temperaturas de entre 30 y $40{ }^{\circ} \mathrm{C}$ de las $12: 00$ a 15:30 horas, y los indicadores más bajos se daban por la noche, entre las 23:00 y 8:00 horas cuando la temperatura disminuía, este efecto también fue registrado por (Bidlingmaier, 2006), (Osorio, Ciro \& González, 2007). y (Rivas Solano, Faith Vargas \& Guillén Watson, 2010), que establece una relación directa entre el aumento de la temperatura, el crecimiento de los microorganismos y la producción de biogás.

Se observó que la fase de hidrolisis, perteneciente a la etapa 1 del proceso se efectuó en un medio con un $\mathrm{pH}$ dentro de los márgenes en la escala, siendo de 6.0 a 6.2 para las bacterias acidogénicas y de 6.5 a 7.5 en las bacterias metanogénicas (Sebastian Nogués, Abián Vicén, Reseau \& García-Galindo, 2010). Sin embargo, el ultimo nivel de $\mathrm{pH}$ registrado en el día 12 , equivalente a 6.3, es un rango límite, ya que para que el proceso anaerobio se desarrolle adecuadamente en el reactor, el $\mathrm{pH}$ óptimo debe de ser alrededor de 7.0, presentando problemáticas significativas, si el $\mathrm{pH}$ es inferior a 6.0 o superior a 8.3 (Acosta \& Obaya, 2005).
En cuanto a la humedad, los valores iniciales fueron de entre $80-90 \%$, registrando un total de $85 \%$. Sin embargo, para el día 12 de producción, los índices de humedad bajaron hasta un $57 \%$.

\section{Conclusiones y recomendaciones}

El gran potencial que presenta el Estado de Sonora en cuanto a la producción de energía por medio de biomasa, es un factor clave para empezar a implementar tecnologías de generación de energías renovables, de bajo costo, con alto desempeño y sobre todo que sean viables, tanto para productores locales, como para ganaderos y poblados aislados de la red eléctrica.

La ventaja principal, dejando de lado la disposición de materia prima que presenta el estado de Sonora para producir energías renovables a través de la biomasa, son las altas temperaturas registradas durante todo el año, por lo cual, independientemente de la estación en la que estemos, la producción de biogás puede ser rentable. Otra ventaja competitiva es que se puede obtener tecnología nacional y del extranjero (principalmente de Estados Unidos) de forma rápida y económica, con capital humanos capacitado para la instalación y mantenimiento de las plantas productoras.

Un inconveniente que presenta la biomasa en el estado, es que compite con la energía solar, siendo esta última una fuente de energía con gran potencial de explotación y mercado la región. Al utilizar tecnologías de monitoreo y sensado de los procesos de generación de energías renovables como el biogás, podemos correlacionar los picos de producción con las condiciones óptimas de biodigestión, así, bajo estos criterios, se pueden establecer los parámetros ideales de temperatura, $\mathrm{pH}$, humedad y nivel, para una producción eficiente de biogás en las condiciones de Hermosillo Sonora.

A nivel tecnológico, para futuras investigaciones, se puede diseñar e implementar una aplicación móvil que sirva como interfaz entre el usuario y lo que realmente está pasando en el proceso, de esta forma, el usuario podrá tomar acciones inmediatas desde un lugar remoto. 
Se pueden implementar medidas de control en situaciones muy extremas, por ejemplo, si los parámetros de $\mathrm{pH}$ se elevan demasiado, se puede accionar una válvula que haga fluir dentro del reactor una sustancia ácida hasta que se regularice el $\mathrm{pH}$, o si disminuye demasiado, verter una sustancia básica.

Para futuros objetivos de investigación, los autores pretenden implementar el sistema en la región de Hermosillo Sonora y monitorear el proceso durante todo el año, con la finalidad de conocer los meses con mayor producción y poder realizar un balance de costos beneficios en la implementación de tecnología para la generación de energía por medio de biomasa.

\section{Referencias}

Acosta, L. \& Obaya, M. (2005). La digestión anaerobia. Aspectos teóricos. Parte I. ICIDCA. Sobre Los Derivados De La Caña De Azúcar, 39 (1), pp. 35-48.

Balcells, J., \& Romeral, J. (1997). Autómatas programables, (pp. 113, 114). Barcelona: Marcombo.

Bidlingmaier, W. (2006). Conference Probes Anaerobic Digestion. BioCycle Journal of Composting and Organics Recycling. Fifth ORBIT, 47(9) , pp. 42-49.

Campos, B. (2011). Metodología para determinar los parámetros de diseño y construcción de biodigestores para el sector cooperativo y campesino. Rev. Ciencias Técnicas Agropecuarias, 20(2).

Campos, E., Elías, X. \& Floats, X. (2012). Procesos biológicos, Madrid: Ediciones Díaz de Santos.

Carrillo, L. (2003). Microbiología agrícola, (1st ed.). Salta: unas.

Esguerra, M. (1989). Experiencias prácticas con biodigestores de bajo costo para la generación de energía y el tratamiento de aguas residuales en países en desarrollo. Conferencia Internacional de Mecanización Agraria. (1st ed., pp. 171-178). Seminario FAO-CNRE: Tecnologías de producción de biogás, España.
Gutiérrez García, G., Moncada Fernández, I., Meza Montenegro, M., Félix Fuentes, A., Balderas Cortes, J., \& Moroyoqui, G. (2012). Biogás: una alternativa ecológica para producción de energí. Ide@S CONCYTEG, 7(85), 881-894.

Hopp, V. (1994). Fundamentos de tecnología química para formación profesional. (1st ed., p. 67). Barcelona: Reverté.

INEGI. (2017). Anuario estadístico y geográfico de Sonora 2016, 1st ed. Hermosillo.

Instituto Nacional de Estadística y Geografía, INEGI. Recuperado de: https://www.inegi.org.mx/contenidos/saladepre nsa/boletines/2018/OtrTemEcon/PIBEntFed201 7.pdf, 2018. [En línea]. Disponible en: http://www.inegi.org.mx/. [Consulta: 02- Sep2018].

Lagrange, B. (1979). Biomethane. Principes, techniques, utilisation (2nd ed., p. 249). Aix-enProvence: Edisud.

Lema, J., \& Méndez, R. (1997). Tratamientos biológicos anaerobios, capitulo en: Contaminación e ingeniería ambiental, volumen III, Contaminación de las aguas (1st. ed.). Oviedo: F.I.C.Y.T.

López Gálvez, U. (2015). Inventario de recursos energéticos de biomasa biodegradable en Sonora (1st ed.). Barcelona: Universidad Politécnica de Cantaluya.

Magaña, L., Torres, E., Martínez, M., Sandoval C., \& Hernández, R. (2011). "Tratamiento anaerobio de desechos lácticos y estiércol de cabra.", Bdigital, vol. 11, no. 1, pp. 93-98.

Melendi, D. (2015). "Metano". [En línea]. Disponible en: http://www.cricyt.edu.ar/enciclopedia/terminos/ Metano.htm. [Consulta: 20- Dic- 2017].

Osorio, J., Ciro, H., \& González, H. (2007). Evaluación de un sistema de biodigestión en serie para clima frío. Rev. Fac. Nal. Agr. Medellín. 60 (2). 
Red Mexicana de Bioenergía, A.C., "Biogás | Red Mexicana de Bioenergía", Rembio.org.mx, 2016. [En línea]. Disponible en: http://rembio.org.mx/areas-tematicas/biogas/. [Consulta: 10- Dic- 2018].

Rivas Solano, O., Faith Vargas, M., \& Guillén Watson, R. (2010). Biodigestores: factores químicos, físicos y biológicos relacionados con su productividad. Tecnología En Marcha, 23(1), 39-46.

Sebastian Nogués, F., Abián Vicén, M., Reseau, A., \& García-Galindo, D. (2010). Energía de la biomasa (1st ed., pp. 216-217). Zaragoza: Prensas Universitarias de Zaragoza.

Servicio Meteorológico Nacional, "Normales climatológicas", SMN, 2017. [En línea]. Disponible en: http://smn.conagua.gob.mx/tools/RESOURCES /Normales8110/NORMAL26139.TXT.

[Consulta: 11- Jun- 20187].

Varnero Moreno, M. (2011). Manual de biogás (1st ed., pp. 84-93). Santiago de Chile: Organización de las Naciones Unidas para la Alimentación y la Agricultura (FAO).

Varnero, M., \& Arellano, J. (1990). Aprovechamiento racional de desechos orgánicos (1st ed.). Santiago de Chile: Ministerio de Agricultura (FIA) y Universidad de Chile.

Wageningen University and Pontificia Universidad Católica de Valparaíso. (2017). "¿Cuál es el pH de los alimentos?", Foodinfo.net. [En línea]. Disponible en: http://www.food-info.net/es/qa/qa-fp65.htm.

[Consulta: 22- Dic- 2017]. 